University of Nebraska - Lincoln

DigitalCommons@University of Nebraska - Lincoln

4-24-1996

\title{
Fabrication of large arrays of micron-scale magnetic features by selective area organometallic chemical vapor deposition
}

D. Welipitiya

University of Nebraska-Lincoln

Y.L. He

University of Nebraska-Lincoln

Jiandi Zhang

Solid State Division, Oak Ridge National Laboratory, jiandiz@lsu.edu

P.I. Oden

Oak Ridge National Laboratory

T. Thundat

Oak Ridge National Laboratory, Oak Ridge, Tennessee

See next page for additional authors

Follow this and additional works at: https://digitalcommons.unl.edu/physicsdowben

Part of the Physics Commons

Welipitiya, D.; He, Y.L.; Zhang, Jiandi; Oden, P.I.; Thundat, T.; Warmack, R.J.; Gobulukoglu, Ismail; Shan, Z.S.; Sellmyer, David J.; and Dowben, Peter A., "Fabrication of large arrays of micron-scale magnetic features by selective area organometallic chemical vapor deposition" (1996). Peter Dowben Publications. 44.

https://digitalcommons.unl.edu/physicsdowben/44

This Article is brought to you for free and open access by the Research Papers in Physics and Astronomy at DigitalCommons@University of Nebraska - Lincoln. It has been accepted for inclusion in Peter Dowben Publications by an authorized administrator of DigitalCommons@University of Nebraska - Lincoln. 


\section{Authors}

D. Welipitiya, Y.L. He, Jiandi Zhang, P.I. Oden, T. Thundat, R.J. Warmack, Ismail Gobulukoglu, Z.S. Shan, David J. Sellmyer, and Peter A. Dowben 


\title{
Fabrication of large arrays of micron-scale magnetic features by selective area organometallic chemical vapor deposition
}

\author{
D. Welipitiya and Y. L. He \\ Center for Materials Research and Analysis, and Department of Physics and Astronomy, \\ University of Nebraska, Lincoln, Nebraska 68588-0111 \\ Jiandi Zhang \\ Solid State Division, Oak Ridge National Laboratory, Oak Ridge, Tennessee 37831 \\ P. I. Oden, T. Thundat, and R. J. Warmack \\ Molecular Imaging Group, Health Sciences Research Division, Oak Ridge National Laboratory, \\ Oak Ridge, Tennessee 37831 \\ Ismail Gobulukoglu, Z. S. Shan, D. J. Sellmyer, and P. A. Dowben ${ }^{\text {b) }}$ \\ Center for Materials Research and Analysis, and Department of Physics and Astronomy, \\ University of Nebraska, Lincoln, Nebraska 68588-0111
}

(Received 28 November 1995; accepted for publication 24 April 1996)

\begin{abstract}
We demonstrate that it is possible to deposit a wide range of magnetic features, using photoassisted selective area organometallic chemical vapor deposition. Large arrays of identical micron-scale $\mathrm{Ni}$ features were deposited on a $\mathrm{Si}(111)$ wafer by this method. Their magnetic properties were studied by alternating gradient force magnetometry as well as magnetic force microscopy. Our morphological and magnetic measurements show that the structures are spatially well defined, and the magnetic properties are related to the structural shapes of the features. This method can be adapted to the fabrication of smaller-scale magnetic and electronic devices. (C) 1996 American Institute of Physics. [S0021-8979(96)04515-X]
\end{abstract}

\section{INTRODUCTION}

The dependence of magnetic properties of a small magnetic feature on both its size and shape is of considerable fundamental interest. ${ }^{1-5}$ Several approaches to fabricating such micron- and submicron-scale metal features have been undertaken, including organometallic chemical vapor deposition (OMCVD) "writing" using scanning tunneling microscopy (STM) ${ }^{5-10}$ and UV photolysis ${ }^{11-13}$ as well as the more conventional electron beam lithography. ${ }^{4-14}$

We have been able to develop the photolysis of organometallic compounds beyond the simple fabrication of magnetic multilayers ${ }^{13}$ to deposit micron-scale magnetic patterns on semiconductor substrates. The photoassisted selective area OMCVD method has advantages not shared by many other techniques. The deposition rate is a few orders of magnitude faster than the STM techniques. The deposition can be performed in ultrahigh vacuum (UHV); thus, with an appropriate choice of source molecules, chemical contamination can be minimized not only within the growing film but at the surface as well. As noted elsewhere, this technique is undertaken at relatively low temperatures so that unusual magnetic multilayers can potentially be fabricated. ${ }^{13}$ This method can yield deposition over a large area in a single-step deposition process. Since there is now enough material for an appreciable signal, magnetic properties can be studied by most magnetometry techniques including in situ measurements, such as magneto-optical Kerr effect. Utilizing a range of masks, diffraction, and relatively short wavelength light

\footnotetext{
${ }^{a}$ Permanent address: Intel Corporation, 2200 Mission College Blvd., P. O. Box 58119, Santa Clara, CA 95052-8119.

${ }^{b)}$ Author to whom correspondence should be addressed.
}

(light in the UV), a variety of magnetic features can be directly deposited over a wide range of size and shape.

An important issue in the ferromagnetic feature fabrication in device applications is the fabrication speed. In our work, the film deposition time is typically approximately $4 \mathrm{~h}$ for a film thickness of several microns. This can be significantly reduced to less than $1 \mathrm{~h}$ by using higher metallocene vapor pressure and higher light intensity. Thus, this method may be suitable for fabrication of small-scale devices.

\section{EXPERIMENT}

Figure 1 shows a schematic of the deposition apparatus. The deposition was performed in a UHV chamber described elsewhere. ${ }^{15}$ The incident radiation for photolysis was supplied by a commercial (Molectron) pulsed laser (at $15 \mathrm{~Hz}$ in this work) with an output in the near ultraviolet region at 337 $\mathrm{nm}$, which corresponds to a photon energy of $3.69 \mathrm{eV}$. For a suitable light intensity and large illumination area, the laser beam was deliberately placed off focus at the substrate surface plane. Quartz lenses were used for the optics. The area of the deposition was typically $3 \mathrm{~mm}^{2}$. A metal grid was used for diffraction of the incident light and as a mask in order to produce the desired patterns. The dimension of the squares in the grid was $20 \times 20 \mu \mathrm{m}^{2}$. The organometallic vapor source, nickelocene, was sublimed from through a variable leak valve. The nickelocene vapor pressure was kept at $3 \times 10^{-5}$ Torr during deposition. 


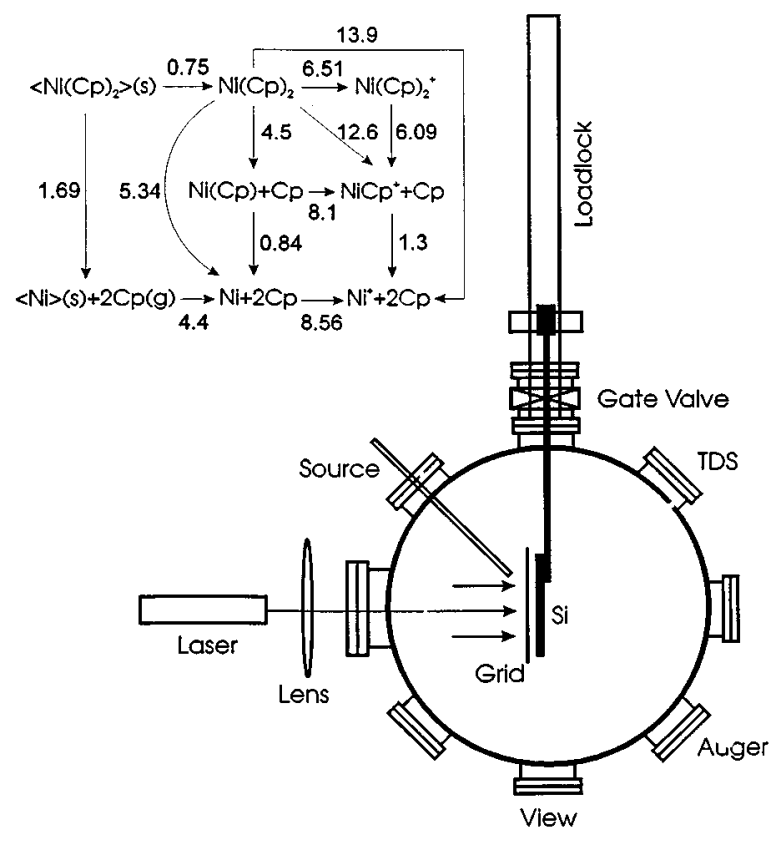

FIG. 1. A schematic of the ultrahigh vacuum deposition apparatus. The substrate is transferred by the loadlock. The UHV chamber is also equipped with Auger electron spectroscopy and thermal desorption spectroscopy capabilities. The inset shows the thermodynamic cycle of nickelocene taken from Ref. 12. All numbers in the inset are in units of eV/molecule.

\section{DEPOSITION}

This work is based upon the characterization of the energetics of nickelocene, $\mathrm{Ni}\left(\mathrm{C}_{5} \mathrm{H}_{5}\right)_{2}$, decomposition. ${ }^{12}$ The energetics of nickelocene decomposition taken from Ref. 12 are shown as the inset of Fig. 1. A single photon process can result in the separation of $\mathrm{Ni}$ atoms from cyclopentadienyl ligands $\left(\mathrm{C}_{5} \mathrm{H}_{5}=\mathrm{Cp}\right)$ in the metallocene molecules at surface, since the energy needed to achieve ligand-metal cleavage is $1.69 \mathrm{eV}$, i.e., $\mathrm{Ni}(\mathrm{Cp})_{2}($ surf $) \rightarrow \mathrm{Ni}(\operatorname{surf}+2(\mathrm{Cp})($ gas $)$, is lower than the photon energy of $\mathrm{N}_{2}$ laser. The dissociation of $\mathrm{Ni}$ atoms from the cyclopentadienyl ligands for the gas phase metallocene requires an energy $(>4.5 \mathrm{eV})$ higher than that of the $\mathrm{N}_{2}$ laser, and two-photon events are unlikely. Thus, photolysis of nickelocene can be used to define the deposition to the illuminated surface regions, and to transfer the illuminated regions into a $\mathrm{Ni}$ pattern on the substrate.

Figure 2(a) shows the scanning electron microscopy (SEM) image of the array of nickel features deposited on silicon with its native oxide film. The nickel array consists of an array of features, $20 \times 20 \mu \mathrm{m}^{2}$. The $20 \times 20 \mu \mathrm{m}^{2}$ squares are slightly distorted due to small distortions of the grid (a close contact mask). At higher magnification, each feature shows a series of fine lines. The fine structure of a typical square is shown in Fig. 2(b). The fine structure spacing and width is about $2 \mu \mathrm{m}$. All the Ni fine structure is connected at a finite thickness. It is worth noting that, as shown in the gray scale, the outermost fine structure lines may be rather thin. The spatial distribution of the $\mathrm{Ni}$ in these patterns was further examined by energy dispersive x-ray spectroscopy. Both Ni and Si peaks are detected within the observed features. In contrast, only the Si peak appears in the dark re-

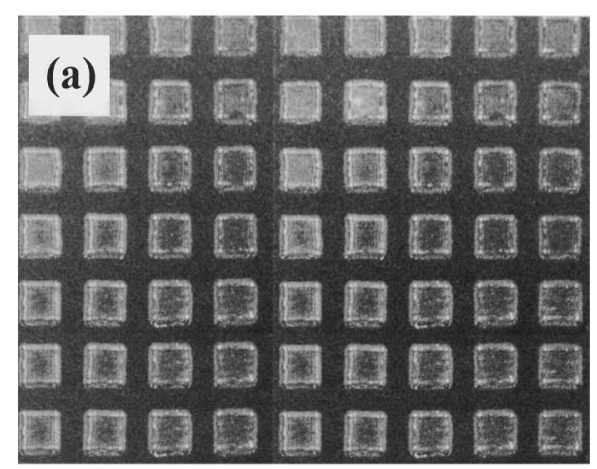

(b)
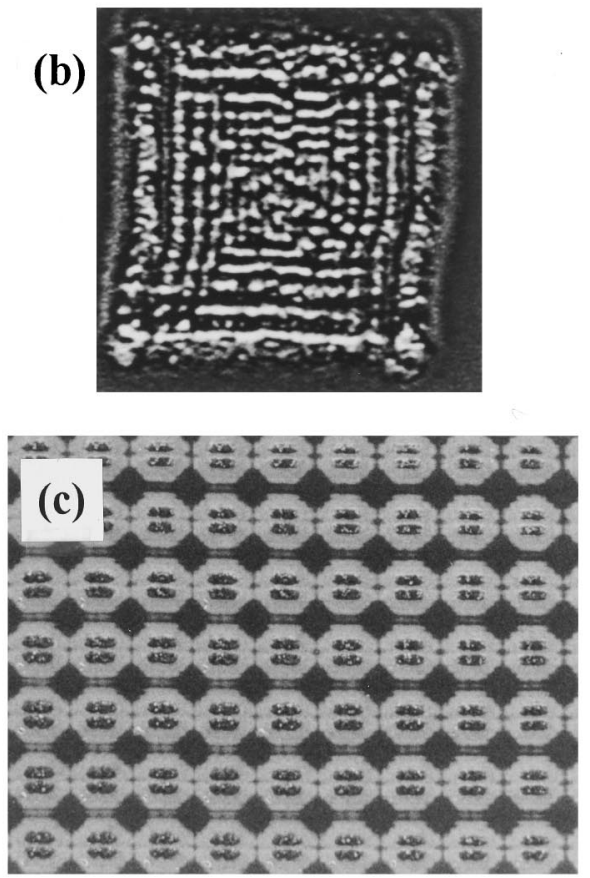

FIG. 2. (a) A SEM image of an array of squarish Ni features on Si substrate. (b) The fine structure of a single feature as shown in (a). (c) SEM image of an array of distinct (" 8 ',-shaped) Ni features on an oxidized Si substrate.

gions between the square features. We can conclude that the nickel is indeed spatially localized.

This is certainly consistent with previously photolytic decomposition studies ${ }^{11}$ and more recent deposition studies of material from ferrocene $\left\{\mathrm{Fe}\left(\mathrm{C}_{5} \mathrm{H}_{5}\right)_{2}\right\}$ using a scanning tunneling microscope. ${ }^{6}$ It may be that for the very most selective area chemical vapor deposition, passivation of the silicon surface is required, as has been recently undertaken in an organometallic chemical vapor deposition study using a scanning tunneling microscope. ${ }^{16}$ Complexes of ferrocene with silicon are indeed known ${ }^{17}$ and anticipated for nickelocene. Thus, the adsorption and desorption of the complete nickelocene molecule may not be as simple as indicated by surface science studies of the similar organometallic, ferrocene, on single crystal metal surfaces. ${ }^{18}$

\section{MAGNETIC CHARACTERIZATION}

Figure 3 shows scanning force and magnetic force microscopy (MFM) images of a sample taken after a few days exposure to atmosphere. A commercially available micro- 

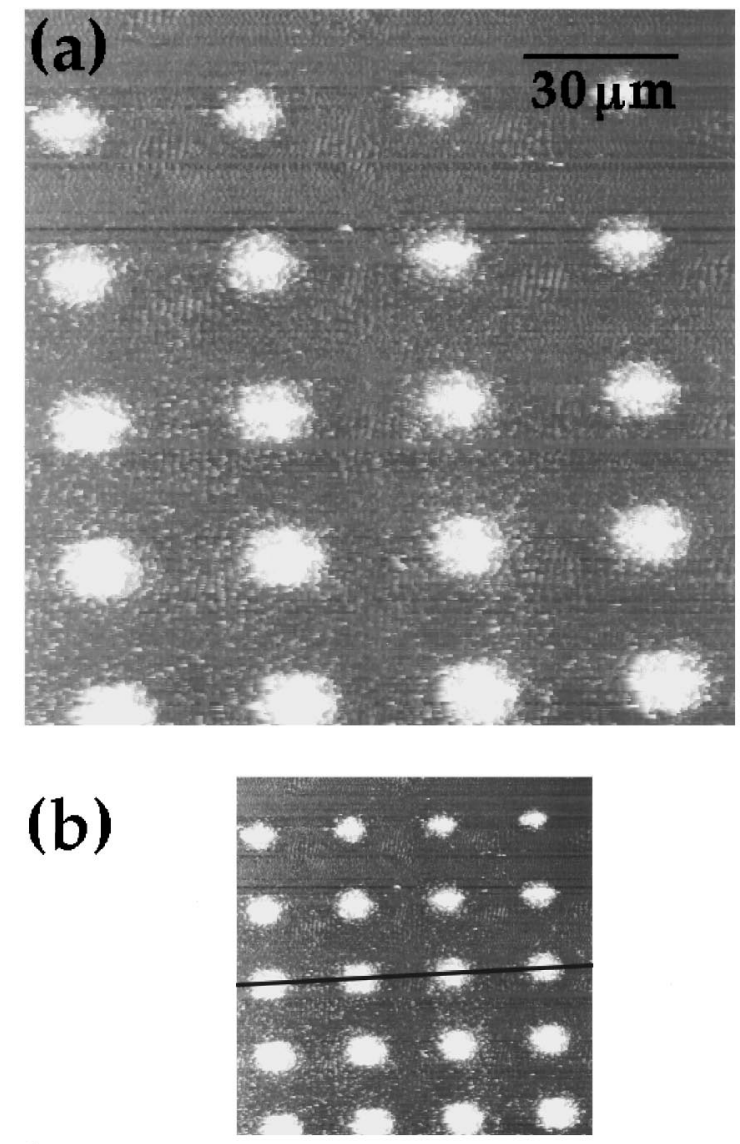

\section{$1 \mu \mathrm{m}$}
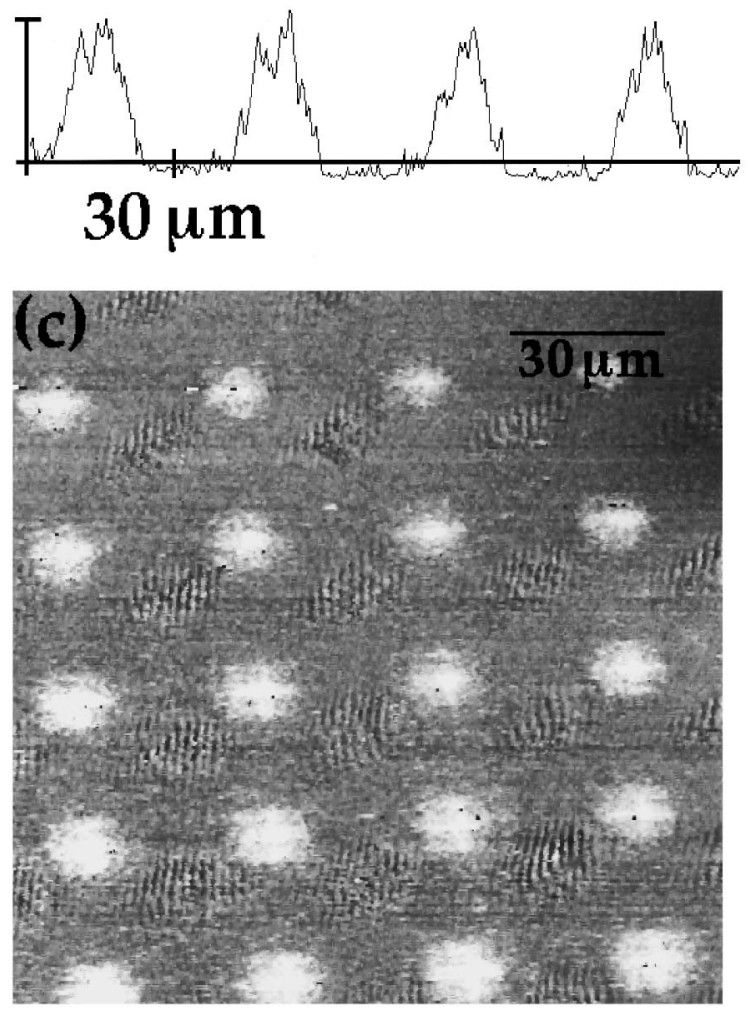

FIG. 3. (a)A $141 \times 141 \mu \mathrm{m}^{2}$ area showing the surface features utilizing the tapping imaging mode. The $z$ scale is $4 \mu \mathrm{m}$ dark to light. (b) Cross-sectional cut through the previous image as shown. (c) Magnetic image of (a), acquired at the same time, with a probe lift-height of $50 \mathrm{~nm}$. The phase contrast range is $\pm 5^{\circ}$. The bright spots indicate attraction between the magnetic tip and the deposited material.

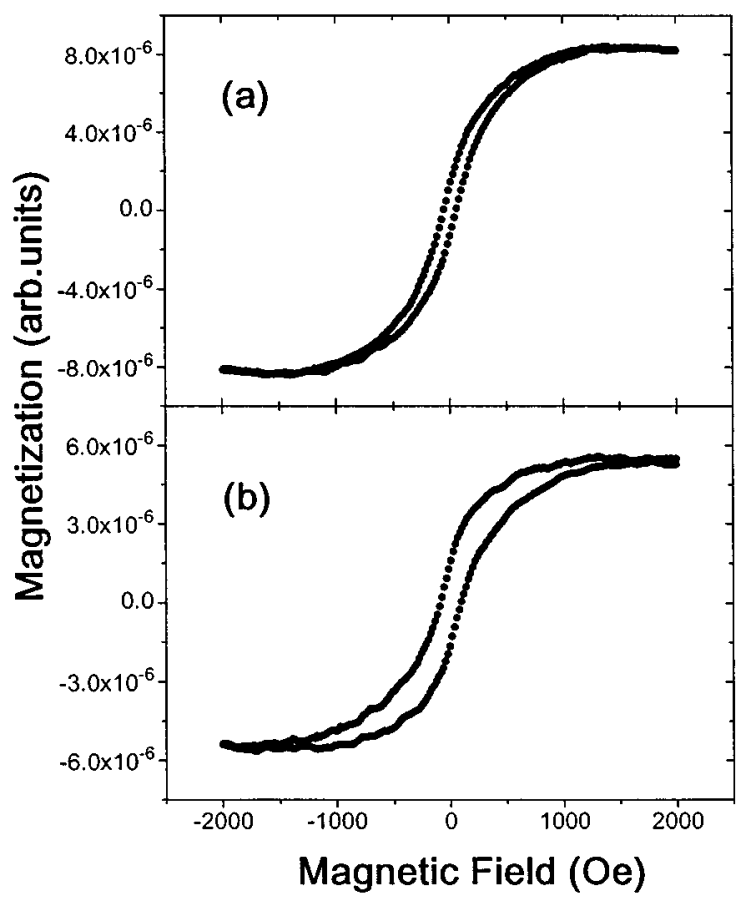

FIG. 4. Magnetic hysteresis loops measured by using an alternating gradient force magnetometer: (a) shows a loop measured from the $\mathrm{Ni}$ array as shown in Fig. 2(a). (b) was measured from the pattern as shown in Fig. 2(c).

scope with magnetized tips was utilized (Nanoscope III, Digital Instruments). The topographic image of the surface was acquired using the standard tapping mode. Magnetic imaging was performed by monitoring the shift in the phase of the resonating cantilever that is scanned at a predetermined height above the sample surface. During the rastering of the image, alternating topographic and magnetic strips of data were acquired. The tapping response image of the surface is shown in Fig. 3(a). This $141 \times 141 \mu \mathrm{m}^{2}$ scan shows a $4 \times 5$ array of the fabricated nickel features. The dimensions are less than $20 \times 20 \mu \mathrm{m}^{2}$, i.e., slightly smaller than the SEM images in Figs. 2(a) and 2(b). This smaller size may be a result of the edge structure dominated by nickel silicides, and contamination. Figure 3(b) displays the typical height through the features and the location of the cross-sectional cut. In the corresponding MFM image of Fig. 3(c), the nickel features appear to be weakly ferromagnetic, as expected, and are seen to be spatially well separated. Also, the integrated volume of the particles is in rough agreement with the magnetization measurements, discussed below. Interference fringes are also visible between the nickel structures and are instrumental in origin, resulting from optical interference of the laser with the surface structures.

Figure 4(a) shows an in-plane magnetic hysteresis loop from the array of nickel squares [Figs. 2(a) and 3]. The loop was measured by a commercial alternating gradient force magnetometer. The saturation field is about $1 \mathrm{kOe}$, and its coercivity is approximately $50 \mathrm{Oe}$. The ratio of the remanence to the saturation magnetization is 0.18 . The hysteresis loops in both the in-plane and perpendicular configurations are nearly identical. This may be because the demagnetiza- 
tion effects of the film are similar in both orientations, since the size of nickel structures is rather small.

To demonstrate the influence of shape on the magnetic properties, we made arrays with differently shaped $\mathrm{Ni}$ features. To do this with the same mask, we changed the diffraction condition so that the laser illuminated a different pattern. Figure 2(c) shows the SEM image of an array of nickel features deposited under such conditions. The film consists of an array of figure " 8 "'-shaped structures. This is a drastically different shape. The size of these features is about $30 \mu \mathrm{m}$. The thickness of the pattern is $\sim 8 \mu \mathrm{m}$, and that of the central crossing line is about $\sim 2 \mu \mathrm{m}$.

The hysteresis loop for an array of these features is shown in Fig. 4(b). The coercivity for the two different arrays is roughly similar, suggesting that the microstructure in both arrays is similar. Besides the difference in saturation magnetization, which is at least partially determined by the total amount of nickel, the hysteresis loop shape is rather different from that for the array of squarelike features. The ratio of remanence to saturation is two times larger for the figure " 8 "'-shaped features, and the saturation field is slightly lower. These differences indicate the hysteresis dynamics are dependent upon the shape of even small volume $\mathrm{Ni}$ structures. Systematic studies of different patterns are planned, and will lead to an improved fundamental understanding of magnetic dynamics. Those studies are currently underway.

The saturation magnetization of the entire array of nickel dots is consistent with the magnetic properties of nickel, if the integral volume of all the nickel features is considered. It may be that the saturation magnetization is, therefore, not dominated by shape for features of these dimensions, but rather by the composition of the material.

\section{SUMMARY}

Our results suggest that it may be possible to make features with a sufficiently small volume so as to limit each feature to a single domain. An array of such single magnetic domains is ideal for the manipulation of magnetic structures, ${ }^{19}$ and to test theoretical models of dynamic behavior $^{20-22}$ without the complications of domain-wall motion.

We have deposited large arrays of micron-scale Ni structures on an oxidized $\mathrm{Si}(111)$ wafer, by using photoassisted selective area organometallic chemical vapor deposition. Drastically different Ni features were obtained by manipulating the laser diffraction conditions. Their magnetic properties are correlated with the shape of the $\mathrm{Ni}$ features. This deposition method demonstrates a new approach for micronscale device fabrication.

\section{ACKNOWLEDGMENTS}

The authors thank R. D. Kirby and K. W. Weirman for their valuable help and comments. This work is supported by the Department of Energy (No. DE-FG0295ER12177.A000); the Division of Materials Sciences, U. S. Department of Energy, under Contract No. DE-AC0584OR21400 with Lockeed Martin Energy Systems, Inc.; the
National Science Foundation (Grant No. OSR-92-55225); and an Alexander Hollaender Distinguished Postdoctoral Fellowship sponsored by the DOE, Office of Health and Environmental Research administrated by Oak Ridge Institute for Science and Education (to PIO).

${ }^{1}$ E. D. Dahlberg and J.-G. Zhu, Phys. Today 48, (4) 34 (1995); D. D. Awschalom and D. P. DiVincenzo, ibid. 48, (4) 43 (1995); D. R. Fredkin and T. R. Koehler, J. Appl. Phys. 67, 5544 (1990).

${ }^{2}$ F. Liu, M. R. Press, S. N. Khanna, and P. Jena, Z. Phys. D 12, 361 (1989); G. C. Papaeffthymiou, Phys. Rev. B 46, 10366 (1992); C. Y. Yang, K. H. Johnson, D. R. Salbub, K. Kaspar, and R. P. Messmer, ibid. 13, 1396 (1976); G. M. Pastor, R. Hirsch, and B. Münhlschlegel, Phys. Rev. Lett. 72, 3879 (1994); W. de Heer, P. Milani, and A. Châtelain, Z. Phys. D 19, 241 (1991).

${ }^{3}$ D. O'Conner and C. R. Stephens, J. Magn. Magn. Mater. 104-107, 300 (1992); M. E. Fisher, ibid. 54-57, 646 (1986); K. Binder, in Phase Transitions and Critical Phenomena, edited by C. Domb and J. L. Lebowitz (Academic, New York, 1985), Vol. 8; H. W. Diehl, in Phase Transitions and Critical Phenomena, edited by C. Domb and J. L. Lebowitz (Academic, New York, 1986), Vol. 10; D. L. Mills, J. Phys. (Paris) Colloq. 31, C1-33 (1970); Takahito Kaneyoshi, Introduction to Surface Magnetism (CRC, Boca Raton, FL, 1991); T. Kaneyoshi, J. Phys. Condens. Mater. 3, 4497 (1991); G. A. T. Allen, Phys. Rev. B 1, 352 (1974); M. E. Fischer and A. E. Ferdinand, Phys. Rev. Lett. 19, 169 (1967); K. Binder, Thin Solid Films 20, 367 (1974); K. Binder and P. C. Hohenberg, Phys. Rev. B 6, 3461 (1972); A. Corcioveei, Czech. J. Phys. B 10, 568 (1960); L. Valenta, Phys. Status Solidi 2, 112 (1962); U. Paschen, C. Sürgers, and H. v. Löhneysen, Z. Phys. B 90, 289 (1993); M. Farle, K. Baberschke, U. Stetter, A. Aspelmeier, and F. Gerhardter, Phys. Rev. B 47, 11571 (1993); U. Stetter, M. Farle, K. Baberschke, and W. G. Clark, ibid. 45, 503 (1992).

${ }^{4}$ C. Shearwood, S. J. Blundell, M. J. Baird, J. A. C. Bland, M. Gester, H. Ahmed, and H. P. Hughes, J. Appl. Phys. 75, 5249 (1994).

${ }^{5}$ D. D. Awschalom, M. A. McCord, and G. Grinstein, Phys. Rev. Lett. 65, 783 (1990); A. D. Kent, T. M. Shaw, S. von Molnar, and D. D. Awschalom, Science 262, 1249 (1993); M. A. McCord and D. D. Awschalom, Appl. Phys. Lett. 57, 2135 (1990); A. D. Kent, S. von Molnar, S. Gider, and D. D. Awschalom, J. Appl. Phys. 76, 6656 (1994).

${ }^{6}$ F. Thibaudau, T. P. Roge, J. R. Roche, Ph. Mathiez, Ph. Dumas, and F. Salvan, Microsc. Microanal. Microstruct. 4, 419 (1993); F. Thibaudau, J. R. Rouche, and F. Salvan, Appl. Phys. Lett. 64, 523 (1994).

${ }^{7}$ A. L. de Lozanne, E. E. Ehrichs, and W. F. Smith, J. Phys. Condens. Matter 5, 409 (1993).

${ }^{8}$ D. S. Saulys, A. Ermakov, E. L. Garfunkel, and P. A. Dowben, J. Appl. Phys. 76, 7639 (1994).

${ }^{9}$ E. E. Ehrichs and A. L. de Lozanne, in Nanostructure Physics and Fabrication, edited by M. A. Redd and W. P. Kirk (Academic, New York, 1989), p. 441; S.-T. Yau, D. Saltz, and M. H. Nayfeh, Appl. Phys. Lett. 57, 2457 (1990).

${ }^{10}$ E. E. Ehrichs, S. Yoon, and A. L. de Lozanne, Appl. Phys. Lett. 53, 2287 (1988); E. E. Ehrichs, R. M. Silver, and A. L. de Lozanne, J. Vac. Sci. Technol. A 6, 540 (1988); R. M. Silver, E. E. Ehrichs, and A. L. de Lozanne, Appl. Phys. Lett. 51, 247 (1987).

${ }^{11}$ Y.-G. Kim, S. Bialy, G. T. Stauf, R. W. Miller, J. T. Spencer, and P. A. Dowben, J. Microstruct. Microfab. 1, 42 (1991); G. T. Stauf and P. A. Dowben, Thin Solid Films 156, L31 (1988); P. A. Dowben, J. T. Spencer, and G. T. Stauf, Mater. Sci. Eng. B 2, 297 (1989); Karl-Heniz Emrich, G. T. Stauf, W. Hirschwald, S. Barfuss, P. A. Dowben, R. R. Birge, and N. M. Boag, in Chemical Perspectives of Microelectronic Materials, edited by Gross, Jasinski, and Yates [Mater. Res. Soc. Symp. Proc. 131, 401 (1989)].

${ }^{12}$ Y.-G. Kim, D. Byun, C. Hutchings, P. A. Dowben, H. Hejase, and K. Schroder, J. Appl. Phys. 70, 6062 (1991); G. T. Stauf, D. C. Driscoll, P. A. Dowben, S. Barfuss, and M. Grade, Thin Solid Films 153, 421 (1987).

${ }^{13}$ S.-D. Hwang, Y. G. Kim, C. Wu, and P. A. Dowben, Mater. Sci. Eng. B 20, L1 (1993).

${ }^{14}$ P. R. Krauss, P. B. Fischer, and S. Y. Chou, J. Vac. Sci. Technol. B 12, 3639 (1994); S. Y. Chou, M. Wei, P. R. Krauss, and P. B. Fischer, ibid. 12, 3695 (1994).

${ }^{15}$ Y. J. Kime, J. Zhang, and P. A. Dowben, Surf. Sci. 268, 98 (1992).

${ }^{16}$ D. P. Adams, T. M. Mayer, and B. S. Swartzentruber, Appl. Phys. Lett. 68, 2210 (1996).

${ }^{17}$ M. Heberhold, Angew. Chem. Int. Ed. Engl. 34, 1837 (1995). 
${ }^{18}$ D. Welipitiya, A. Green, J. Woods, P. A. Dowben, B. W. Robertson, D. Byun, and J. Zhang, J. Appl. Phys. (in press); D. Welipitiya, P. A. Dowben, J. Zhang, W. W. Pai, and J. F. Wendelken, Surf. Sci. (in press).

${ }^{19}$ G. A. Gibson and S. Schultz, J. Appl. Phys. 73, 4516 (1993); R. Wiesendanger, J. Vac. Sci. Technol. B 12, 515 (1994).

${ }^{20}$ See, e.g., D. Heitmann, T. Demel, K. Kern, P. Grambow, K. Ploog, and Y. H. Zhang, in Nanostructures and Mesoscopic Systems, edited by W. P. Kirk and M. A. Reed (Academic, New York, 1991), p. 335.
${ }^{21}$ R. D. Kirby, J. X. Shen, R. J. Hardy, and D. J. Sellmyer, Phys. Rev. B 49, 10810 (1994); Z. S. Shan, J. X. Shen, R. D. Kirby, and D. J. Sellmyer (unpublished).

${ }^{22}$ M. Rao and A. Chakrabarti, Phys. Rev. Lett. 72, 2911 (1994); M. Rao, ibid. 68, 1436 (1992); M. Rao, H. R. Krishnamurthy, and R. Randit, Phys. Rev. B 42, 856 (1990); W. S. Lo and R. A. Pelcovits, Phys. Rev. A 42, 7471 (1989); L. J. Challis, Contemp. Phys. 33, 111 (1992). 